\title{
A Case of Intraoral Drainage of latrogenic Parotid Sialocele after Sialendoscopy
}

\author{
Jun Woong Song, Hyoung Shin Lee, Kang Dae Lee, and Sung Won Kim \\ Department of Otolaryngology-Head and Neck Surgery, Kosin University College of Medicine, Busan, Korea \\ 타액선관 내시경술 후 발생한 의인성 이하선 타액류의 경구배액술 1예
}

송준웅 · 이형신 · 이강대 · 김성원

고신대학교 의과대학 이비인후과학교실

\author{
Received August 29, 2014 \\ Revised October 26, 2014 \\ Accepted November 4, 2014 \\ Address for correspondence \\ Sung Won Kim, MD \\ Department of Otolaryngology- \\ Head and Neck Surgery, \\ Kosin University \\ College of Medicine, \\ 262 Gamcheon-ro, Seo-gu, \\ Busan 602-702, Korea \\ Tel +82-51-990-6247 \\ Fax +82-51-245-8539 \\ E-mail swforyou@hanmail.net
}

A variety of treatment methods have been proposed for parotid sialocele. These include multiple aspirations and compression dressings, reconstruction of the duct, creation of a controlled internal fistula, superficial or total parotidectomy, radiation therapy and ductal ligation, etc. Most of these procedures are invasive with variables and often with poor success rates. This paper presents an unusual incidence of iatrogenic parotid sialocele after sialendoscopy and its management by a relatively simple, safe and effective technique, which is constituted of draining saliva into the intraoral.

Korean J Otorhinolaryngol-Head Neck Surg 2015;58(8):572-5

Key Words Iatrogenic parotid sialocele $\cdot$ Intraoral drainage $\cdot$ Sialendoscopy $\cdot$ Silicone tube.

\section{서 론}

타액류의 치료는 대개의 경우 반복적인 흡인 및 압박을 하 는 보존적인 방법이지만, 호전되지 않는다면 수술적인 치료 가 필요하며, 손상받은 위치에 따라 다양한 수술방법이 보고 되고 있다. ${ }^{1,2)}$ 본 증례에서는 타액선관 내시경술 후 합병증으 로 이하선 타액류가 발생하였으며, 보존적인 치료에도 호전 을 보이지 않아서, 구강을 통해 타액류에 실리콘 관을 유치하 고, 관을 따라 타액이 배액되는 경로를 새로 만들어 주어 치 료하였다. 이에 타액선관 내시경술 후 이하선 타액류가 발생 하는 것이 드물며, 이후 타액류를 치료한 방법이 안전하고 간 단하며 효과적이어서 문헌고찰과 함께 보고하는 바이다.

\section{증 례}

34세 여자 환자가 내원 수개월 전부터 발생한 구강건조증
상과 양측 이하선 부위의 종창을 주소로 본원 이비인후과 외래 방문하였다. 경부 컴퓨터단층촬영(CT)에서 양측 이하 선의 실질과 이하선관 내의 석회화 소견은 없었으나, 양측 이 하선 전반에 걸쳐 경미하게 조영이 증강되며 부어 있었다. 만 성 이하선염, 이하선관의 협착 의진 하에 타액선관 내시경술 을 시행하였고, 내시경상 만성염증으로 인한 분비물(sludge) 과 함께 이하선관의 내경이 전반적으로 좁아진 것을 확인하 였다. 이에 관내를 충분히 세척하고 수압을 이용해 넓혀 주었 으며, 당시 주의할만한 손상은 관찰되지 않았다(Fig. 1).

하지만, 술 후에 우측 이하선 협부의 종창이 더욱 심화되었 으며, 초음파에서 우측 이하선 타액류가 관찰되었다(Fig. 2). 흡인을 하여 약 $15 \mathrm{cc}$ 정도를 배액하고 압박치료를 하였으나 큰 호전 없이 종창이 반복되어 수술을 계획하였다.

우선 초음파를 이용해 타액류의 위치와 모양을 확인한 뒤, 구강을 통해 타액류와 가장 가까운 협부 점막에 국소마취를 하고 약 $1 \mathrm{~cm}$ 가량 절개하여 저류된 타액의 일부를 배액하였 

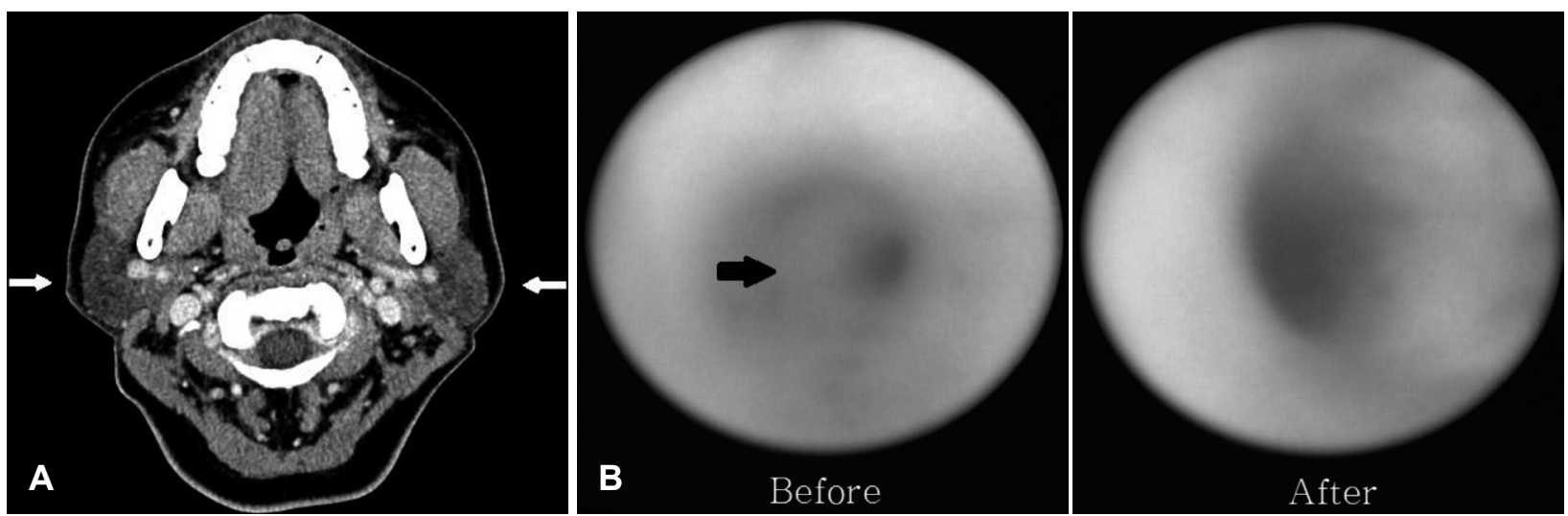

Fig. 1. Neck CT scan shows diffuse enlargement and mild enhancement in both parotid lesion (arrow) without remarkable calcification (A). Sialendoscopy shows sludge and narrowing lumen in right parotid duct (before) (arrow), and the lumen was dilated after irrigation without remarkable injury (after) (B). And left parotid duct finding is similar to right.

Fig. 2. Preoperative photograph shows asymmetric swelling in right cheek (arrow) (A). Neck USG scan shows $2 \times 1 \mathrm{~cm}$ sized hypo-echoic cyst in right buccal space (B).
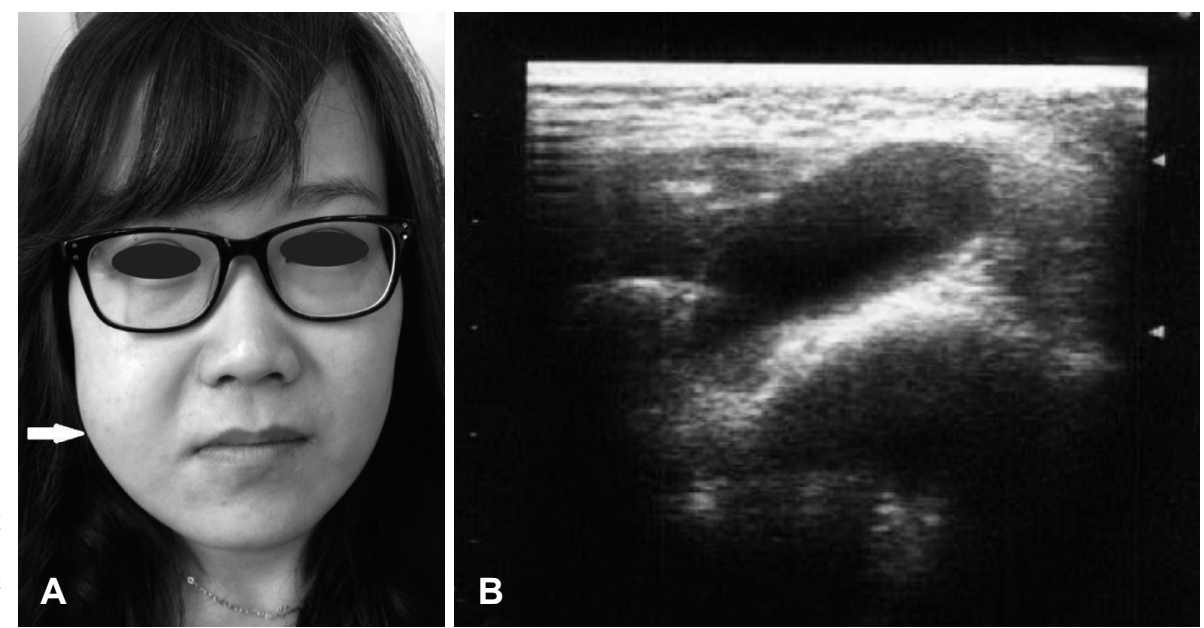
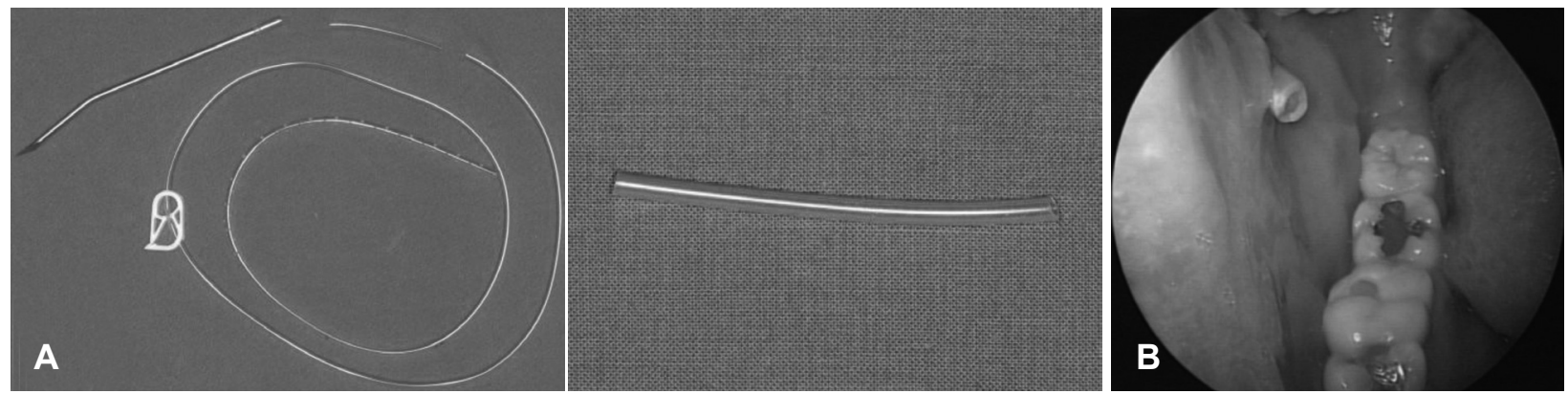

Fig. 3. Photograph shows drainage tube that was made by cutting $4 \mathrm{~cm}$-length from the distal end of the Jackson-Pratt drain tube (A). Laryngoscopy shows Jackson-Pratt drain tube fixed at buccal mucosa. The tube connected sialocele with oral cavity draining saliva (B).

다. 이후 Jackson-Pratt drain 관을 약 $4 \mathrm{~cm}$ 가량 잘라 실리 콘 관을 만들고, 이 관을 한쪽은 타액류 내에 반대쪽은 구강 내로 위치하게 삽입하고 협부점막에 4/0 vicryl 봉합사로 고 정하였다(Fig. 3). 관은 협부점막에 비스듬하게 고정하여 이 물감이 적고, 저작 시 방해되지 않게 하였다. 이후 관을 통해 타액이 배액되는지를 경과관찰하고, 술 후 3주째에 제거하였 다. 현재 술 후 1 년째로 재발 및 특이소견 없이 경과관찰 중 이다(Fig. 4).

\section{고 찰}

타액류는 타액관 주변에 타액이 모여 낭종 모양을 이룬 것 으로, 그 기전은 주로 염증, 타석, 종양 등에 의해 타액관의 일 부가 손상되어 생기는 경우와, 수술로 인해 관이 손상을 받아 타액이 관외로 유출되는 경우가 있다. 유출된 타액은 주변조 직과 염증반응을 일으켜 육아조직으로 둘러싸이면서 가성 낭종이 된다. ${ }^{34)}$ 발생한 타액류의 협부조직 외부로 부드럽고 


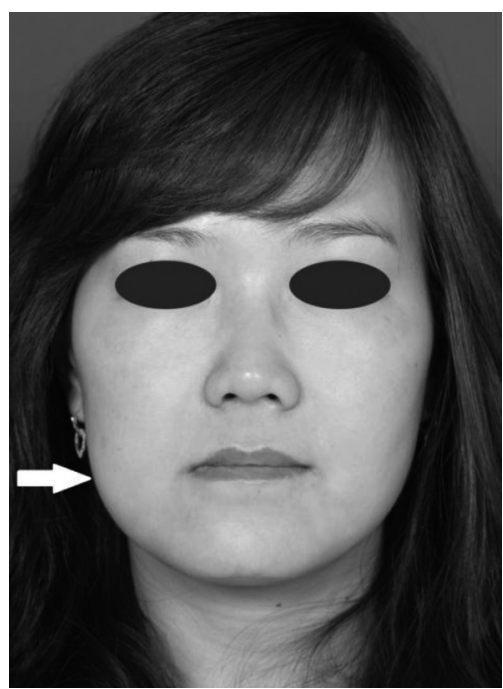

Fig. 4. Postoperative photograph shows symmetry in both cheeks (arrow) without swelling.

통증이 없는 종창이 나타나고, 시간이 지나면서 점차 커지게 된다. 간혹 협부의 피부 쪽으로 누관이 생겨 미용적으로 심 각한 문제를 유발하기도 한다. ${ }^{3}$

진단은 흡인을 통해 무색 투명한 끈적한 액체를 확인하고, 아밀라아제(amylase) 성분을 검출하면 타액류를 쉽게 확인 할 수 있다. 영상학적 검사로는 경부 컴퓨터단층촬영(CT)에 서 주변조직보다 낮은 음영의 표면이 매끈한 낭종 모양으로 관찰되고, 초음파 검사를 해보면 쉽게 그 위치와 모양을 확 인할 수 있다. 타액선조영술(sialography)을 하면 타액류의 범 위, 관이 손상받은 위치를 확인할 수 있어 수술계획을 세우 는 데 도움이 되기도 한다. ${ }^{5)}$

타액선관 내시경술은 타액선관을 내시경적 시야를 통해 진 단 및 치료를 할 수 있는 우수한 방법으로 문헌에 따르면 술 후 합병증의 빈도는 약 10 12\%로 보고되며 이 중 추가 치료가 필 요한 심한 합병증은 드문 편이다. 가장 흔한 합병증은 타액선 의 부종으로 시술 당시 세척 관류를 계속하므로 거의 모든 사 례에서 발생하고 술 후 1 일 내에 모두 자연 치유된다. Walv$\mathrm{ekar}$ 등은 56 명의 환자에서 타액선관 내시경술 후 $2 \%$ 에서 주 요합병증, $23 \%$ 에서 경한 합병증을 보고하였다. ${ }^{67}$

본 증례에서는 타액선관 내시경술 후 1 일 이후에도 우측 이하선 협부의 종창이 지속되어 이하선관의 손상을 의심하 였고, 초음파를 통해 타액류를 확인하고 흡인을 통해 아밀라 아제 성분을 검출하여 진단하였다. 이하선관이 손상된 이유로 는 타액선관 내시경술을 시행할 때 이하선관의 개구부와 내 경이 매우 좁은 상태에서 무리하게 진행하였기에 외상이 발생 한 것으로 판단하였다.

타액류가 발생하면 흡인을 하고 압박하는 것이 일반적이 지만, 호전이 없을 경우에는 수술적인 치료를 고려해야 하고,
손상받은 위치에 따라 다양한 수술방법이 소개되었다. ${ }^{1,2)}$ 수 술방법은 주로 세 가지로 나뉘는데, 타액분비를 억제하는 방 법, 타액을 구강 내로 배액해주는 방법, 그리고 관을 봉합하 는 방법 등이다. ${ }^{8-10)}$ 보고된 많은 수술방법들이 다소 어렵고 치료 성공률도 비교적 낮았으나, 몇몇 문헌에서 실리콘 관을 통해 타액을 구강 내로 배액 하는 방법이 비교적 쉽고, 성공 률도 약 $92 \%$ 정도로 높아 효과적인 방법으로 소개되었다. ${ }^{3.9)}$ 이 문헌들을 검토해보면 첫 번째 방법은 환자를 전신마취를 한 후에, 피부를 절개하고 타액류를 찾고, 그 심부에서 구강 점막으로 다시 절개하여 관의 한쪽 끝을 구강 내로, 다른 한 쪽 끝을 타액류 내로 위치하여 구강 점막에 관을 고정한 후 피부를 봉합하는 방법이고, 두 번째 방법은 환자를 전신마취 를 한 후에 구강 내로 투관침(trocar) 또는 직경이 큰 캐뉼라 (cannula)를 타액류 내로 넣어 관을 유치하는 방법이다.

결국 타액류 내로 관을 정확하게 넣는 것이 중요한데, 본 증 례에서는 초음파를 사용하여 타액류의 위치를 정확하게 파 악하였고, 배액관 삽입 시 배액관의 한쪽 끝이 타액류 내로 위치하는 것을 확인할 수 있었기 때문에, 간단하면서도 안전 하게 시술을 마칠 수 있었다.

그 외에 보존적인 치료 방법으로는 최근에 보튤리늄 톡신을 이하선이나 피하조직으로 주입하는 방법이 보고되고 있으 며, ${ }^{8,11)}$ 타액분비를 억제하는 약물을 보조적으로 사용할 수 있 다. 방사선 치료를 하였다는 보고도 있지만, 이 자체가 다른 부 작용이나 합병증을 유발할 수 있기 때문에 선호되지 않는다.12)

앞서 소개하였듯이 타액선관 내시경술 후 의인성 이하선 타액류가 발생하는 것이 드물며, 또한 타액류의 치료로 실리 콘 관을 통해 구강으로 배액한 방법이 안전하고 간단하면서 효과적이라 문헌고찰과 함께 보고하는 바이다.

\section{REFERENCES}

1) Baurmash HD. Obstructive parotid ductal disease: intraoral management. J Oral Maxillofac Surg 2007;65(9):1886-91.

2) Steinberg MJ, Herréra AF. Management of parotid duct injuries. Oral Surg Oral Med Oral Pathol Oral Radiol Endod 2005;99(2): 136-41.

3) Canosa A, Cohen MA. Post-traumatic parotid sialocele: report of two cases. J Oral Maxillofac Surg 1999;57(6):742-5.

4) Lapid O, Kreiger Y, Sagi A. Transdermal scopolamine use for postrhytidectomy sialocele. Aesthetic Plast Surg 2004;28(1):24-8.

5) Parekh D, Glezerson G, Stewart M, Esser J, Lawson HH. Posttraumatic parotid fistulae and sialoceles. A prospective study of conservative management in 51 cases. Ann Surg 1989;209(1):105-11.

6) Choi JS, Lim JY, Kim YM. Sialendoscopy. Korean J OtorhinolaryngolHead Neck Surg 2011;54(12):819-27.

7) Walvekar RR, Razfar A, Carrau RL, Schaitkin B. Sialendoscopy and associated complications: a preliminary experience. Laryngoscope 2008;118(5):776-9.

8) Arnaud S, Batifol D, Goudot P, Yachouh J. Nonsurgical management of traumatic injuries of the parotid gland and duct using type a botulinum toxin. Plast Reconstr Surg 2006;117(7):2426-30. 
Intraoral Drainage of latrogenic Parotid Sialocele I Song JW, et al.

9) Edkins O, van Lierop AC, Fagan JJ, Lubbe DE. Peroral drainage of posttraumatic sialocoeles: report of three cases. J Laryngol Otol 2009;123 (8):922-4.

10) Sulabha AN, Sangamesh NC, Warad N, Ahmad A. Sialocele: an unusual case report and its management. Indian J Dent Res 2011; 22(2):336-9.
11) Vargas H, Galati LT, Parnes SM. A pilot study evaluating the treatment of postparotidectomy sialoceles with botulinum toxin type A. Arch Otolaryngol Head Neck Surg 2000;126(3):421-4.

12) Capaccio P, Paglia M, Minorati D, Manzo R, Ottaviani F. Diagnosis and therapeutic management of iatrogenic parotid sialocele. Ann Otol Rhinol Laryngol 2004;113(7):562-4. 